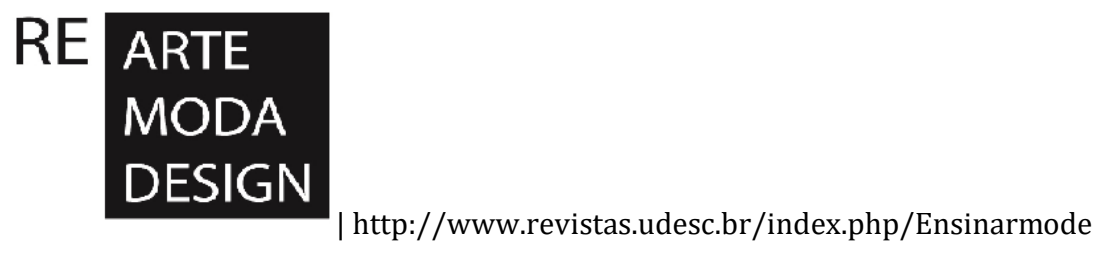

\title{
MEMÓRIAS DA ACADEMIA: O ENSINO DA ARTE NO INÍCIO DA REPÚBLICA
}

Camila Dazzi ${ }^{1}$

\section{RESUMO}

Os anos de 1880 no Brasil são conturbados, não somente no plano político, mas igualmente no plano cultural - o Império de Dom Pedro II agoniza. O golpe final à Monarquia brasileira ocorre em novembro de 1889, com a proclamação da República. No plano cultural, os anos finais da Academia Imperial de Belas Artes seguiram os rumos do Império. Com o advento da República uma ansiada reforma da Academia se tornou realidade, ocasionando a transformação da instituição em Escola Nacional de Belas Artes. A Reforma de 1890 trouxe alterações efetivas para o sistema de ensino artístico da instituição, muitas delas em plena sintonia com os novos preceitos adotados pelo Governo Republicano via Ministério da Educação.

Palavras-chave: Escola de Belas Artes. República Brasileira. Ensino de Arte.

\footnotetext{
${ }^{1}$ Realizou estágio Pós-doutoral, como bolsista da CAPES, junto à Università degli Studi di Napoli Federico II/Itália (2013). É doutora em Teoria da Arte pela Escola de Belas Artes da UFRJ (2011), Mestre em História da Arte pelo Instituto de Filosofia e Ciências Humanas da UNICAMP (2006) e graduada em Artes Plásticas pela Universidade Federal do Rio de Janeiro (2003). É professora adjunta do CEFET/RJ, atuando na graduação e na pós-graduação.

E-mail: camiladazzi@gmail.com | Lattes: http://lattes.cnpq.br/4381920068622016.

Revista ENSINARMODE, Florianópolis, Vol. 1, N. 1, Outubro 2017 - Janeiro 2018, p. 009-026.

DOI: http://dx.doi.org/10.5965/25944630112017009 | ISSN 2594-4630
} 


\section{RE ARTE \\ MODA \\ DESIGN}

| http://www.revistas.udesc.br/index.php/Ensinarmode

\section{INTRODUÇÃO}

Os anos de 1880 no Brasil são extremamente conturbados, não somente no plano político, mas igualmente no plano cultural. O Império de Dom Pedro II agoniza diante das críticas feitas pelos abolicionistas e pelos republicanos. $\mathrm{O}$ golpe final à Monarquia brasileira ocorre em novembro de $1889 \mathrm{com}$ o apoio dos militares, que insatisfeitos com desprestígio da carreira militar, são aqueles que irão efetivamente proclamar a República Brasileira e assumir o comando do país. No plano cultural, verificamos que anos finais da Academia Imperial de Belas Artes seguiram os rumos do Império. Não é desconhecido daqueles que estudam a arte brasileira do século XIX o fato de que, durante a década de 1880, a Academia foi alvo de desaprovações dos críticos de arte e também de alguns de seus professores, alunos e diretores. Multiplicavam-se as críticas que exigiam uma renovação urgente da estrutura e dos métodos de ensino da instituição, do mesmo modo que se exigia uma reestruturação política do país. Com o advento da República a ansiada reforma se tornou uma realidade, com a implementação da chamada Reforma de 1890 e a transformação da instituição em Escola Nacional de Belas Artes.

Acreditando que a Reforma de 1890 - a qual pôs fim à Academia de Belas Artes e instituiu a Escola Nacional de Belas Artes. O texto que o leitor passa agora a ler possui um objetivo principal: não houve somente uma mera mudança do nome da instituição; propomo-nos também a compreender como a Reforma foi concebida pelos artistas que com ela estiveram envolvidos e verificar em que medida as propostas apresentadas naquele momento estavam em sintonia com as mudanças advindas do novo regime em tão em vigor - a República.

Nossa tentativa não é infundada, pois o que se verifica é que, apesar de sua significativa importância, o papel desempenhado pela Escola Nacional de Belas Artes assim como o de seus professores, no decorrer da década de 1890, não mereceu ainda a revisão que lhe é devida. Como explicar a falta de interesse por esse período?

Tal limitação historiográfica pode ser elucidada, principalmente, graças ao notório antiacademicismo que vigorou até bem pouco tempo na cena artística brasileira e que propagou a ideia recorrente de passividade generalizada da Escola Revista ENSINARMODE, Florianópolis, Vol. 1, N. 1, Outubro 2017 - Janeiro 2018, p. 009-026. DOI: http://dx.doi.org/10.5965/25944630112017009 | ISSN 2594-4630 


\section{RE ARTE \\ MODA \\ DESIGN}

| http://www.revistas.udesc.br/index.php/Ensinarmode

em relação à modernidade. Principalmente após a Reforma de 1890, a instituição foi apresentada sempre como um lugar de conformismo, homogeneamente resistente às mudanças.

Popularizado já desde fins do século XIX, sobretudo na fala dos críticos de arte, esse antiacademicismo associou à Escola Nacional de Belas Artes à imagem de uma instituição retrógrada, avessa a quaisquer inovações estéticas e alienadas da realidade brasileira. Tal imagem forjada pela pena dos então críticos da instituição ${ }^{2}$ tornou-se, nas décadas iniciais do século $\mathrm{XX}$, uma das peças centrais daquilo que poderíamos chamar «mito fundador» do modernismo brasileiro, que nada mais fez do que incorporar a «ideia força do ideário modernista francês, qual seja, a da exigência de se formular uma revolta contra as instituições artísticas, contra os mandarins dos Salons» (Marques, 2001: 21-23).

A tendência é perceptível na escassa fortuna crítica sobre a Escola no decorrer das três primeiras décadas do século XX. Para não nos prolongarmos muito, podemos citar aqui dois nomes de destaque do meio artístico carioca: o pintor Modesto Brocos, que, em seu livro A Questão do Ensino de Bellas Artes Seguido da Crítica Sobre a Direção Bernardelli e Justificação do Autor, afirmou que o ensino ministrado na instituição «continuou a ser em seu fundo, ensino e disciplinas, pouco mais ou menos do que era no tempo do Império ou, para falar com franqueza, a mesma cousa» (Brocos, 1915: 44-45); e o crítico de arte Gonzaga Duque, que, no seu famoso livro Contemporâneos, asseverou ter sido a Reforma de 1890 uma mera «questão de rótulo». (Duque Estrada, 1929: s/p).

Essas afirmações, no entanto, como procuraremos demonstrar, são bastante unilaterais e não devem ser tomadas como "verdades absolutas» pelos pesquisadores interessados na história da Escola. Além disso, devemos considerar o fato de que tais críticas, que serviram de base para outras que se sucederam, foram escritas anos após os acontecimentos que circundaram a Reforma de 1890, quando a instituição já havia passado por outras reformulações, como as de 1901 e de 1911, além da que estava se processando em 1915.

2 Esse antiacademicismo é, por exemplo, um dos poucos traços constantes no pensamento crítico de Gonzaga Duque e pode ser detectado também no círculo de intelectuais vinculados à célebre Revista Illustrada, como Angelo Agostini. 


\section{RE ARTE \\ MODA \\ DESIGN}

| http://www.revistas.udesc.br/index.php/Ensinarmode

\section{CONTEXTO HISTÓRICO E BENJAMIN CONSTANT}

$\mathrm{Na}$ Primeira República, a evolução das ideias pedagógicas se caracterizou por dois movimentos ideológicos: o «entusiasmo pela educação» e o «otimismo pedagógico» (Nagle, 1974: 35). Esses movimentos atribuíram importância cada vez maior à instrução nos diversos níveis. Com características distintas, se desenvolveram através de movimentos político-sociais e programas de diferentes organizações. Nesse sentido, serviam a propósitos de natureza política, daí a importância que foi atribuída à educação como solução dos graves problemas nacionais.

Vigorosas discussões e tomadas de posição acerca das precárias condições da educação escolar brasileira já se faziam presentes nas últimas décadas do Império, herdando à República, em rico legado, propostas que visavam repensar os problemas educacionais do país. O «entusiasmo pela educação» nasceu nesse contexto e trouxe à tona o teor de descompromisso educacional do poder público, realçando a necessidade de expansão da escola primária alfabetizadora. Passados os primeiros anos de implantação do regime republicano, o fervor das discussões arrefeceu (Oliveira, 2006: 1-10).

A Reforma Benjamin Constant, 1890/1891, foi a primeira reforma educacional do período republicano, estando no ápice de mudanças conjunturais advindas da Proclamação da República, e, portanto, configurando-se como a ressonância de um ambiente marcado por rearranjos políticos, novas ideologias e, sem dúvida, transformações culturais.

Benjamin Constant foi ministro dos Negócios da Instrução Pública, Correios e Telégrafos durante o governo provisório presidido por Deodoro da Fonseca, cargo esse que serviu para Constant empreender a Reforma da Instrução Pública Primária e Secundária do Distrito Federal e a Reforma do Ensino Superior, além da criação do Conselho de Instrução Superior do Distrito Federal.

O Ministério dos Negócios da Instrução Pública, Correios e Telégrafos foi criado através do Decreto n. 346, de 19 de abril de 1890 e teve curtíssima duração de 1890 a 1892. Para essa nova pasta foram transferidos, do Ministério da Justiça e Negócios Interiores, os assuntos relativos à Instrução Pública, aos Estabelecimentos de Educação e Ensino Especial ou Profissional, aos Institutos, Academias e 


\section{RE ARTE \\ MODA \\ DESIGN}

| http://www.revistas.udesc.br/index.php/Ensinarmode

Sociedades dedicadas às Ciências, Letras e Artes, e do Ministério da Agricultura, Comércio e Obras Públicas, os serviços dos Correios e Telégrafos. Já desde fins do Império, a instituição de tal pasta era solicitada, tendo sua Majestade, em sua última fala do trono, pedido empenho para a constituição de um ministério destinado aos negócios da Instrução Pública.

Tanto Benjamin Constant, quanto o Ministério dos Negócios da Instrução Pública, Correios e Telégrafos tiveram rápida passagem na história da educação, mas não por isso pouco expressiva. As propostas de reforma que vigoraram nos anos finais do século XIX são particularmente significativas para compreendermos o pensamento pedagógico dos anos de 1889, 1890 e 1891; momento no qual os Estatutos de 1890 da Escola Nacional de Belas Artes foram concebidos.

Por certo, nesse contexto, o ensino das belas artes não poderia ser deixado de lado, sendo incorporado, por meio da aprovação dos Estatutos da Escola Nacional de Belas Artes, e assinado por Benjamin Constant em 8 de novembro de 1890.

Tendo como fonte primária documentos de época, é possível identificarmos uma série de relações entre os Estatutos de 1890 da Escola Nacional de Belas Artes e a Reforma da Educação de Benjamin Constant. Por isso, acreditamos ser fundamental pensar a Reforma da Academia de 1890 dentro do contexto mais amplo do qual ela fez parte, qual seja, a reforma colocada em andamento pelo ministro dos Negócios da Instrução Pública, Correios e Telégrafos em 1890/91. A Reforma da Academia não pode, portanto, ser analisada isoladamente do restante das reformas educacionais que ocorreram no país. Pontos indicadores de uma série de relações entre os princípios que guiaram a formulação dos Estatutos de 1890 da Escola Nacional de Belas Artes e aqueles que conduziram a Reforma da Educação de Benjamim Constant. Entre eles se destacam: o ensino pensado de forma seriada, o uso sistemático do método intuitivo, a importância atribuída ao preparo intelectual e o fim dos preceitos e doutrinas na educação.

\section{O ENSINO NA ANTIGA ACADEMIA SEGUNDO RODOLPHO BERNADELLI}

Rodolpho Bernardelli foi o primeiro Diretor da Escola Nacional de Belas Artes, tendo sido nomeado ainda em novembro de 1890. Escultor, formado na 


\section{RE ARTE \\ MODA \\ DESIGN}

| http://www.revistas.udesc.br/index.php/Ensinarmode

antiga Academia, Rodolpho foi um dos idealizadores do projeto da reforma de 1890 . Compreender as mudanças pelas quais passaram a instituição significa, sem sombra de dúvidas, igualmente entender a forma como Rodolpho Bernardelli pensava o ensino artístico do seu tempo, uma vez que ele ficou a frente da instituição como diretor, durante mais de uma década. Não é difícil percebermos, pela leitura de documentos de época, que Rodolpho tinha um pensamento sobre a educação que se aproximava daquele de Benjamin Constant. No Relatório de 1891, encontramos algumas explicações para as mudanças contempladas na Reforma de 1890. Vejamos com que termos Bernardelli se refere à antiga Academia e à sua reforma:

Transformação radical e completa, mais do que simples reforma, foi o decreto de 8 de novembro. Substituindo a Academia creou-se a Escola Nacional de Bellas Artes, que pôde definir todo o seu programa na repulsa com que foi condennado o título pretencioso e nefastamente sugestivo de sua antecessora. A Academia era a contemplação ritual do passado; era a veneração do canon inviolável das convenções plásticas dos antigos, distrahindo o espírito dos artistas do espetáculo ensinador da natureza, era a lição tyrannica do como viam, contrapondo-se ao ensino intuitivo e natural do como vêdes; era o academismo, em suma, com todas as suas modestas ambições de corrigir a scena das cousas. [...] O próprio Director, que ultimamente presidia os destinos da academia, apezar de meio vencido pelo embate dos princípios modernos, que iam innovando no ensino alguns professores de nomeação recente, deixava-se reconhecer, num disfarce mal arranjado dos seus preconceitos, quando escrevia no relatório de 1888. "... a Academia das Bellas Artes, cuja missão actual não deve ser outra mais que a de exclusivamente votar-se ao verdadeiro culto da forma esthetica da arte clássica e da sua propagação evolucionista fomentadora do aperfeiçoamento da arte moderna"... a Academia era, assim, a convenção irremediavelmente revoltada contra a impressão (grifos nossos). (Bernardelli, 1891: 13-14). ${ }^{3}$

Passamos assim, a tratar de outra faceta de Bernardelli que aqui se apresenta: o Bernardelli educador. O escultor se coloca, como então se colocava qualquer educador do momento, ligado ou não ao mundo das artes, contra um "ensino tirânico», no qual o professor bloqueava a individualidade do aluno, contrapondo-se a um «ensino intuitivo».

Rodolpho Bernardelli demonstrou estar em sintonia com o descontentamento de uma significativa parcela de artistas e intelectuais europeus (igualmente norte e sul-americanos) em relação à maneira como o ensino artístico era conduzido no interior das academias. 'Acadêmico' se tornou uma palavra

\footnotetext{
${ }^{3}$ Optamos por manter, nos textos de época, a grafia original encontrada.

Revista ENSINARMODE, Florianópolis, Vol. 1, N. 1, Outubro 2017 - Janeiro 2018, p. 009-026. DOI: http://dx.doi.org/10.5965/25944630112017009 | ISSN 2594-4630
} 


\section{RE ARTE

pejorativa, sinônimo de tradição esclerosada e pedagogia ultrapassada. A crescente importância atribuída à autenticidade e à originalidade levava o ensino nas academias a ser compreendido como demasiado regularizador, inibidor da individualidade dos jovens artistas. (Bouillon, 1990: 35).

Nessa perspectiva, compreendia-se que o 'velho sistema de ensino oficial' precisava ser reformado. Louis Vitet, em seu artigo publicado na Revue des deux mondes em 1864, afirmava que a base do decreto de 1863, que havia reformado a École des Beaux-Arts, era desenvolver nos jovens a originalidade pessoal:

Organizar de tal modo o ensino das artes para que antes de qualquer coisa, ele desperte e desenvolva nos alunos uma originalidade pessoal, tal é a ideia fundamental, a razão de ser do decreto. Leia-o, consulte o relatório que the serve de prefácio, estude as respostas e as apologias da administração; por toda a parte encontrará este mesmo pensamento, que a originalidade pessoal está em perigo em nosso país e que é necessário lhe socorrer. [...] Até que enfim aí estão eles, livres! A era da originalidade começa! Tal é destacado serviço que o decreto, de boa fé, acredita prestar à arte, à juventude e a genialidade francesa (grifos nossos). (Vitet, 1864:74$108)^{4}$

O decreto de 1863 colocou o antigo sistema de ensino no papel de um

poder imóvel, inflexível e inimigo de toda independência, destituído de espaço para os sentimentos individuais de cada um dos alunos que ingressavam na instituição antes da reforma. ${ }^{5}$

Ainda nesse sentido, existe outra passagem no Relatório de Rodolpho Bernardelli ao Ministro que merece ser destacada:

Também foi condenado o ensino especial da esthetica [presente na Academia]. O critério do bello formar-se-ha na consciência do alunno, si for um espirito capaz de synthese [...] formar-se-ha espontaneamente com a summa das doutrinas que professores habilitados the forem ministrando em cada matéria; nascerá como uma opinião individual da simples convivencia e pratica com o alto objecto de sua estudiosa applicação. (Bernardelli, 1891: 18).

\footnotetext{
4 No original: «Organiser de telle sorte l'enseignement des arts qu'avant tout ilexcite et développe chez les élèves' originalité personnelle, telle est l'idée fondamentale, la raison d'être du décret. Lisez-le, consultez le rapport qui lui sert de préface, étudiez les réponses et les apologies de l'administration; partout vous trouverez cette même pensée, que l'originalité personnelle est chez nous en péril et qu'il faut lui porter secours. [...] Enfin les voilà libres! l'ère de l'originalité commence! Tel est le signalé service que le décret, de bonne foi, croit rendre à l'art, à la jeunesse et au génie français ". Disponível no site da Bibliothéque National de France: <http://www.gallica.fr>.

5 Também Alain Bonnet coloca que "L’originalité fut le mot d’ordre de la réforme »', em seu livro L'enseignement des arts au XIXe siècle. La réforme de l'École des beaux-arts de 1863 et la fin du modèle académique. p. 281. 


\section{RE ARTE \\ MODA \\ DESIGN}

| http://www.revistas.udesc.br/index.php/Ensinarmode

A passagem justifica a ausência do ensino da estética, apontando o critério do "que é ou não belo" como algo individual. Não deveria haver, portanto, nenhum pressuposto. Na nova Escola não existia espaço para um pensamento como aquele registrado por Ernesto Gomes Moreira Maia em 1888, ano em que foi nomeado diretor da Academia; segundo o qual a missão da instituição não devia ser "outra mais do que a de exclusivamente voltar-se ao verdadeiro culto da pureza estética da arte clássica e da sua propagação» (Maia, 1889, s/p).

Outro ponto significativo no relatório do diretor da Escola Nacional de Belas Artes é a forma como ele opõe ao ensino ministrado anteriormente na Academia àquele formulado no Projeto de Reforma de Bernardelli e Amoêdo e que foi mantido nos Estatutos de 1890; que propunha uma estrutura seriada de ensino, pensada de forma progressiva. Nas palavras do próprio Bernardelli (1891:18):

$\mathrm{Na}$ organização didática dos novos estatutos reina, sobretudo, o primeiro dos elementos de que deriva a efficácia de qualquer estudo - a sistemática.

Como conjunto teórico, ahi está preparada a seriação dos conhecimentos, de maneira que o aluno progrida dos mais accessiveis aos mais difíceis, na razão do desenvolvimento das faculdades e o tempo dos exercícios (grifos nossos).

Podemos compreender a importância de um ensino seriado quando, mais à frente em seu relatório, Rodolpho Bernardelli (1891:14-15) relembrou a desordem que reinava na Academia em relação à sistematização do ensino. Parece ter sido grande a concomitância entre disciplinas nos anos de 1880 , quando o artista atuou como professor de estatuária na Academia:

A Academia era o academicismo, foi dito.

Nem isso era... [...] A Academia era pura e simplesmente um descalabro. No terreno dos princípios a velha instituição era o academismo - em derrota. [...] Praticamente, concretizando-se em ensino, a desordem era mais flagrante e a mais funesta. [...] A incoerência rudimentar dos estatutos acadêmicos consummava o ideal de organização, que eram os estudos.

Não se havendo classificado os trabalhos n'uma série evolutiva que fossem ao mesmo tempo a ordem e a facilidade, só o improviso dos diretores determinava aos alunos o seguimento do curso.

Sucedia que era proferido dentro da lei para primeira applicação de actividade dos alunnos o estudo do desenho figurado, como poderia dentro da mesma lei ser preferido o da pintura histórica.

Não se havendo preestabelecido legalmente a duração dos estudos, vicio de omissão a respeito de tempo em harmonia com a omissão a respeito da 


\section{RE ARTE \\ MODA \\ DESIGN}

| http://www.revistas.udesc.br/index.php/Ensinarmode

ordem, os alumnos, sem o devido preparo, adiantavam - segundo o capricho da maior ou menor impaciência que, como geralmente os que aprendem, ardiam por escapar à aprendizagem. A simples vigilancia dos exames e concursos não podia marcar a necessaria demora nos estudos (grifos nossos).

As disciplinas, que no nos Estatutos de 1890 antecediam o ensino no atelier de pintura, poderiam ser cursadas simultaneamente às classes de pintura histórica e de pintura de paisagem na antiga Academia, uma vez que não eram pré-requisitos. Fica evidente, assim, a falta de ordem que imperava antes da Academia ser reformada. Na Escola, as coisas passaram a ser diferentes. Segundo Bernardelli (1891:18):

Em complemento do methodo [refere-se à seriação do ensino] evitou-se o mais possível a ampliação dispersiva das especialidades, buscando pela maior generalidade simplificar os estudos. O ensino especial da paisagem foi abolido em attenção a que a paisagem é apenas uma ramificação da pintura. Pôde ser preferida por talento de certa índole; mas o ensino das escolas não deve referir-se particularmente a taes ou taes preferencias do talento, sinão á vantagem do seu cultivo em geral. O ensino especial da paisagem aos especialmente dotados do talento do paizagista acarretaria em parallello o ensino especial da marinha, e o da pintura das flores, etc., para cada um dos quaes tantas vezes ha propensão exclusiva na alma do artista. [...]

Assim, lemos do próprio punho de Rodolpho Bernardelli a explicação para se unir em um só curso todas as especializações da pintura que antes havia na Academia. Certamente que esse é o exemplo mais notório da tentativa de não cercear a personalidade do artista em formação, a possibilidade de permitir o acesso a todas as tendências artísticas. Liberdade, eis uma palavra que vemos surgir com frequência no relatório de Rodolpho Bernardelli. E ainda que palavras como sistematização e seriação pareçam não combinar muito bem com liberdade, devemos ter em mente que reformar o «ensino esclerótico» da Academia significava, naqueles anos, organizar o próprio sistema de ensino, abolindo disciplinas que direcionavam a forma de ver dos alunos, como aquela de estética, e fundindo outras que delimitavam a capacidade artística. A ideia de liberdade, de livre acesso às artes também se estendia para a esfera administrativa:

Administrativamente [na Escola], a organização do ensino não se podia em verdade fazer melhor. Para salvar a boa ordem dos estudos, pelos quaes as responsabilizasse a Escola; para salvar simultaneamente a conveniencia do livre aprender, adaptaram os novos estatutos systema mixto, regularisandoo perfeitamente. De uma parte, existem as matrículas, a obrigatoriedade de Revista ENSINARMODE, Florianópolis, Vol. 1, N. 1, Outubro 2017 - Janeiro 2018, p. 009-026.

DOI: http://dx.doi.org/10.5965/25944630112017009 | ISSN 2594-4630 


\section{RE ARTE \\ MODA \\ DESIGN}

| http://www.revistas.udesc.br/index.php/Ensinarmode

frequencia, os exames, os concursos praticos, os premios em geral, os diplomas, o grande prêmio de viagem para aquelles que resolverem cingirse ao plano rigoroso da preparação escolar; de outra parte, para equelles que não quiserem filiar-se a este regimen, existe a livre frequencia permittida, sem direito a prêmios ou diplomas escolares [...](Bernardelli, 1891:14-15)

A «liberdade de ensino» na Escola igualmente se expandia aos professores:

A liberdade do ensino não somente a respeito ao discipulo foi contemplada. Em relação ao mestre, para prevenir todo risco de academismo ex-cathedra, ficou estabelecido que qualquer cidadão de capacidade notória ou que prove, tem o direito de abrir em sala do edificio ou dependencia da Escola cursos de ensino co-relativo ao escolar, isentos absolutamente de fiscalização doutrinaria official (grifos nossos). (Bernardelli, 1891:19)

De fato, na Europa, a concepção de um ensino artístico possuidor de maior «liberdade» estava largamente difundida, e vemos esse conceito aparecer em diferentes textos. O clima de liberdade de direcionamento no que se refere à École des Beaux-Arts pode ser sentido em um relatório do senador Lambert de SainteCroix, quando fez parte de uma comissão de reorganização dos serviços administrativos das Belas Artes, em 1878, dez anos após a Reforma de 1863:

Se existe um país no mundo onde todas as escolas vivem e se desenvolvem com toda a liberdade, onde a diversidade dos gêneros seja no momento a mais completa, onde se sinta menos a palavra de ordem vinda de cima, é infalivelmente aquele que é acusado de querer dar à arte um carimbo oficial e que, em efeito, é quase o único na Europa a possuir uma administração de Belas Artes. (Larroumet, 1895: 193). ${ }^{6}$

O relatório de Rodolpho Bernardelli esclarece outros posicionamentos que guiavam as intenções dos jovens artistas; uma delas se refere à exclusividade do professorado público das artes plásticas aos portadores de diplomas da Escola Nacional de Belas Artes:

Ligam-se, todavia, tão intimamente ao exito dos intuitos da Escola Nacional de Bellas-Artes, que, em Conclusão ao presente relatório, julgo do meu dever offérecel-os ao exame de vossa esclarecida opinião o ao favor de vosso patrocínio.

\footnotetext{
${ }^{6}$ No original: “ S’il est un pays au monde où toutes les écoles vivent et se développenton toute liberté, où la diversité des genres soit à celle heure la plus complète, où l'on sente moins le mot d'ordre venu d'en haut, c'est à coup sûr celui qu'on accuse de vouloir donner à l'art un cachet officiel et qui, en effet, presque seul en Europe, possède une administration des Beaux-Arts ».

Revista ENSINARMODE, Florianópolis, Vol. 1, N. 1, Outubro 2017 - Janeiro 2018, p. 009-026. DOI: http://dx.doi.org/10.5965/25944630112017009 | ISSN 2594-4630
} 


\section{RE ARTE \\ MODA \\ DESIGN}

| http://www.revistas.udesc.br/index.php/Ensinarmode

Em primeiro locar, seria de imennsa vantagem que os iniciadores da lei em nosso paiz reservassem exclusivamente para os portadores de diplomas da Escola Nacional o direito ao professorado publico das artes plásticas em qualquer grito de desenvolvimento. A organização insuspeita do proprio ensino de mais apertada disciplina na Escola, autoriza a instituição dessa exigência, que forçaria a procura desse ensino, que promoveria assim mais extenso o das aptidões artísticas além de ser uma justa consideração para com os victoriosos do trabalho e da perseverança nas aulas da Escola (grifos nossos) (Bernardelli, 1891: 20).

Verificamos então, que a Escola Nacional de Belas Artes não se propunha somente a formar artistas, ela se propunha a formar professores para atuação nas escolas públicas da República. Rodolpho Bernardelli, perspicaz como era, sabia que não havia mercado de arte no Brasil suficientemente vasto para todos os artistas que saíam formados da Escola Nacional de Belas Artes, assim como sabia dos planos do Governo em estabelecer nas escolas o ensino do desenho. De fato, algumas disciplinas que aparecem na grade curricular apresentada nos Estatutos de 1890 (Decreto ํ‥ 938) estavam direcionadas nesse sentido, quer seja da atuação dos artistas como professores nas escolas primárias, secundárias e de ensino normal.

Curso Geral:

10 Ano do Curso Geral

História Natural (noções concretas)

Mitologia

Desenho Linear

Desenho Figurado (estudo elementar)

20 Ano do Geral

Química e Física

Geometria Descritiva.

Trabalhos gráficos e correspondentes

Arqueologia e etnografia

Desenho figurado

3o Ano do Geral

História das Artes

Perspectivas e Sombras.

Trabalhos gráficos e correspondentes

Elementos da arquitetura decorativa e desenho elementar de ornatos.

Desenho Figurado

Cursos Especiais:

No Curso de Pintura

10 Ano

Anatomia e fisiologia artísticas

Modelo Vivo

20 ano e 30 Anos

Pintura (duas cadeiras)

No Curso de Escultura

10 Ano

Anatomia e fisiologia artísticas 


\title{
RE ARTE \\ MODA \\ DESIGN
}

| http://www.revistas.udesc.br/index.php/Ensinarmode

\author{
Modelo Vivo \\ Escultura de Ornatos \\ 20 ano e 30 Anos \\ Estatuária
}

Disciplinas como fisiologia das paixões e anatomia artística, passaram a fazer parte do Curso Especial, ou seja, eram compreendidas como disciplinas que somente os alunos mais adiantados deveriam aprender. Já a disciplina de modelo vivo só poderia ser cursada depois do Curso Geral.

Um ponto expressivo dos Estatutos de 1890 é o reconhecimento de que o aluno precisava de um significativo cabedal de conhecimentos teóricos antes de chegar de fato às aulas de escultura e pintura. Existia uma eminente preocupação com o preparo intelectual daqueles que se destinam à profissão artística. E esse foi um ponto que mobilizou os artistas e intelectuais no sentido de reformarem o sistema de ensino artístico seja na Europa, seja no Brasil.

Também sabemos que a importância atribuída ao cultivo intelectual do artista encontrou eco nas palavras de críticos que se dedicaram às belas artes da época, como Gonzaga Duque.

Ainda nesse sentido, sabemos que o sistema de ensino da École parisiense pode ter sido uma das fontes de inspiração para a grande importância que se passou a atribuir à formação intelectual dos artistas no Brasil. Como bem colocou Monique Segré, o ensino da cultura geral na École só teve maior destaque nos anos de 1880 e partia do princípio de que o artista deveria não somente adquirir o perfeito domínio técnico, mas também possuir uma cultura excepcional: «L'artiste doit être un homme cultivé» (Segré, 1993: 116). Essa frase que então vigorava, demonstra uma mudança de concepção.

Certamente o ponto mais inovador dos Estatutos de 1890 é a concepção do ensino pensado de forma seriada, mas a percepção do quanto essa proposta é inovadora só surge a partir da comparação com a proposta anterior de ensino, que vigorou na Academia até 1890. Para tanto, é necessário analisarmos as mudanças que ocorrem entre os Estatutos de 1855 e os de 1890.

Sabemos que os Estatutos de 1855 sofreram modificações entre o ano que vigorou e o de 1890 - um intervalo de 35 anos. E ainda que o sistema de ensino da Academia Imperial de Belas Artes tenha sido taxado de 'estacionário', as 


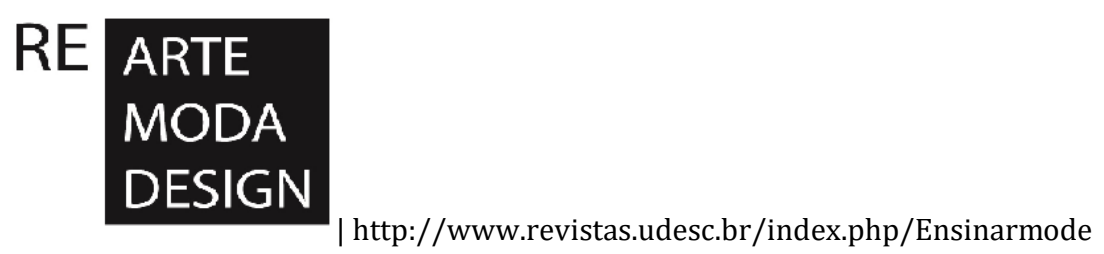

mudanças realmente ocorreram. Existe, porém, certa dificuldade em rastrear essas mudanças, como citado em um trecho do já mencionado Relatório de 1891, redigido por Rodolpho Bernardelli (1891:16):

\begin{abstract}
A única legislação da casa eram os anachronicos estatutos de da Lei. $n$. 1603 de 14 de maio de 1855, assignados pelo Ministro Pedreira, era escassa em recursos; não tinham a elasticidade indispensável ás molas administrativas. Não Ihe valiam pendiculos diversos que espaçadamente se Iho foram acrescentando.

Bem digna imagem de semelhante ruína era aquele pobre canhanho, mal asseiado e roto, metade impresso, metade rabiscado a penna e a lápis, infestado de retalhos de jornal, que foi por longuíssimos anos o raro e único exemplar completo dos estatutos acadêmicos, tristíssimo documento que o derradeiro chefe administrativo da Academia das Belas Artes teve o bom gosto de consumir.
\end{abstract}

A mais significativa dessas mudanças, acrescentadas aos Estatutos de 1855 à «penna e lápis» foi aquela de 1859, estabelecida pelo Decreto No. 2424 de 25 de maio, que dividiu o ensino da instituição em dois cursos, um noturno e um diurno, sendo o noturno voltado para a formação específica de artífices.

Vejamos como passou a se estruturar a Academia em 1855, após a Reforma Pedreira. O ensino ficou dividido em 5 sessões:

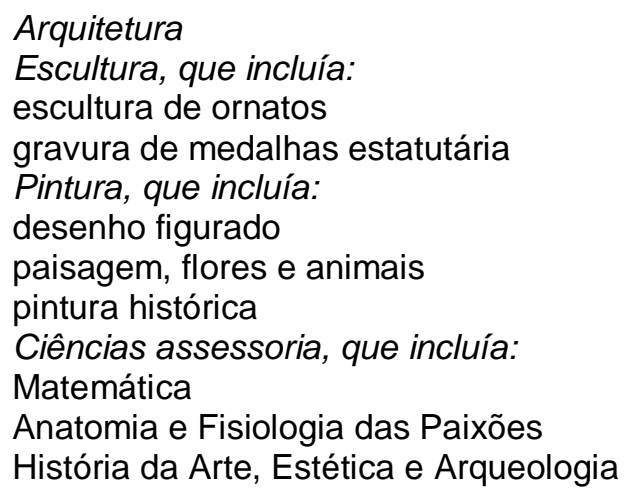

Já aqui é possível encontrar um ponto de divergência em relação aos Estatutos de 1890, que pensava o curso por ciclos que preparavam o aluno para o objetivo final, quer sejam os cursos de pintura, escultura e arquitetura. O Curso Preparatório, após a Reforma de 1890, era obrigatório a todos os alunos e levava um considerável tempo para ser cursado, ao todo três anos e somente após a sua conclusão o aluno poderia chegar aos ateliers do Curso Especial. A pergunta que surge da comparação entre as duas propostas - a de 1855 e a de 1890 - é: após a Reforma Pedreira, o aluno iniciava os seus estudos diretamente com a pintura? Não 


\section{RE ARTE \\ MODA \\ DESIGN}

| http://www.revistas.udesc.br/index.php/Ensinarmode

era necessário antes, como no tradicional sistema de ensino francês, ter o domínio do desenho?

A progressão dos alunos, antes e após a Reforma Pedreira, estava longe de ser tão sistematizada quanto a que passou a vigorar com os Estatutos de 1890.

Como podemos perceber, através dos Estatutos de 1855, todos os alunos eram obrigados a frequentar $a$ «ํํำ série» da disciplina de desenho geométrico e industrial antes de se decidirem por um ramo artístico. ${ }^{7}$ Essa série durava um ano, e o professor deveria ensinar desenho das figuras geométricas, três ordens gregas e teoria das sombras. Se o aluno não se mostrasse habilitado, repetiria todo esse ano. Simultaneamente o aluno era obrigado a cursar a classe de matemáticas aplicadas, responsável por ensinar estereotomia, trigonometria e perspectiva, obrigando os alunos a realizarem exercícios práticos e gráficos; exercícios de levantamento de plantas e nivelamento de terrenos. Somente após os referidos estudos, o aluno poderia escolher entre pintura, escultura, arquitetura e gravura.

O segundo passo na formação do aluno que pretendia cursar, por exemplo, pintura histórica era frequentar a classe de desenho figurado. Conforme a Seção VIII, o desenho figurado era dividido em duas séries: a de cópia de estampas e a de cópia do natural, ou seja, do claro-escuro. O professor deveria empregar todos os seus esforços para o aluno aperfeiçoar «a arte do bem contornar e do exprimir com perfeições as formas por meio da luz». ${ }^{8} \mathrm{O}$ ensino dessa matéria não tinha tempo limitado, ou seja, não tinha duração específica, ficando dependente da aptidão do aluno à sua passagem para as outras aulas, que seria determinado pelo corpo acadêmico. Seus pré-requisitos: matemáticas aplicadas e desenho geométrico.

Assim, para seguir para a classe de pintura histórica bastava o aluno ter sido aprovado nessas três disciplinas: desenho geométrico, matemáticas aplicadas e desenho figurado. Para seguir para a classe de pintura de paisagem, o processo era ainda mais simples: bastava a aprovação na classe de matemáticas aplicadas e desenho geométrico. $O$ aluno não se via obrigado a cursar desenho figurado para

\footnotetext{
7 Estatutos da Academia das Bellas Artes referentes ao Decreto No 1630 de 14 de maio de 1855. s/p.

8 Estatutos da Academia das Bellas Artes referentes ao Decreto No 1630 de 14 de maio de 1855. s/p. Revista ENSINARMODE, Florianópolis, Vol. 1, N. 1, Outubro 2017 - Janeiro 2018, p. 009-026. DOI: http://dx.doi.org/10.5965/25944630112017009 | ISSN 2594-4630
} 


\section{RE ARTE \\ MODA \\ DESIGN}

| http://www.revistas.udesc.br/index.php/Ensinarmode

fazer essa disciplina, embora pudesse cursar as duas ao mesmo tempo, caso o desejasse.

Com o Decreto №. 2424 de 25 de maio de $1859^{9}$ a formação dos artistas (pintores e escultores) não sofreu muitas alterações. Na realidade, o Decreto de 1859 intensificou a possibilidade dos alunos cursarem simultaneamente aulas que passariam a ser pensadas de forma encadeada a partir de 1890. A mudança mais significativa foi a extinção da cadeira de desenho geométrico e industrial. O desenho industrial virou uma disciplina específica para o curso noturno e o desenho geométrico foi diluído na matemática, que passou a ser constituída de duas divisões.

Vejamos como passou a se dar a sistemática de matrícula nos cursos e as habilitações que se tornaram obrigatórias a partir de 1859 (Decreto n. 2424):

Art. 4. A matrícula nas diversas aulas fica subordinada ás seguintes condições:

1.1 Para a matrícula nas aulas de mathematicas applicadas, na de desenho figurado, e na de paizagem será exigido o exame de que trata o Art. 39 dos Estatutos, caso não seja apresentada certidão de approvação passada pelos estabelecimentos publicos de instrucção.

$2.3 \mathrm{Na}$ de modelo vivo será exigida habilitação em estudos de desenho de gesso.

3.1 $\mathrm{Na}$ de desenho figurado, e na de paizagem será exigido pelo menos do segundo anno em diante, matricula simultanea nas aulas de mathematicas; devendo os alumnos que frequentarem a aula de desenho figurado matricular-se no de anatomia, logo que não haja incompatibilidade nas horas de estudo.

4.1 $\mathrm{Na}$ de pintura historica será exigida habilitação em desenho figurado, e nas materias das duas aulas do mathematicas, e matricula simultanea na aula de anatomia e physiologia das paixões.

Assim, para o aluno se matricular em desenho figurado ou pintura de paisagem não havia necessidade de ter cursado anteriormente nem mesmo as aulas de matemática. Cursar as aulas de pintura de paisagem se tornou ainda mais simples após o Decerto de 1859.

Já para cursar pintura histórica foi feita mais uma exigência que não havia anteriormente: além da habilitação nas matemáticas aplicadas e no desenho figurado, o aluno deveria cursar simultaneamente as aulas de fisiologia das paixões.

\footnotetext{
9 Decreto No. 2424 de 25 de maio de 1859 que altera várias disposições dos Estatutos vigentes da Academia das Bellas Artes.
} 


\section{RE ARTE \\ MODA \\ DESIGN}

| http://www.revistas.udesc.br/index.php/Ensinarmode

O modelo vivo não era uma obrigatoriedade, embora o Decreto determinasse que «sempre que for necessário haverá modelo vivo nas aulas de pintura histórica e estatuária».

Assim, o que verificamos é que grande parte das disciplinas que foram colocadas como obrigatórias nos Estatutos de 1890, podiam ser, na antiga Academia, simplesmente nem cursadas, como é o caso do desenho figurado, que na estrutura dos Estatutos de 1890 era obrigatória durante três anos consecutivos. Ou ainda: disciplinas que nos Estatutos de 1890 antecediam o ensino no atelier de pintura poderiam ser cursadas simultaneamente às classes de pintura histórica e de pintura de paisagem na antiga Academia, uma vez que não eram pré-requisitos.

Devemos lembrar aqui das palavras de Rodolpho Bernardelli, em seu Relatório (1891: 14-15), sobre a concomitância desordenada entre disciplinas na Academia, em que a sequência não era pensada «n'uma série evolutiva», sendo, segundo Rodolpho, o improviso dos diretores o único fator que determinava aos alunos o seguimento do curso. Assim, «sucedia que era proferido dentro da lei para primeira applicação de actividade dos alunnos o estudo do desenho figurado, como poderia dentro da mesma lei ser preferido o da pintura histórica».

\section{CONCLUSÃO}

A título de conclusões finais, acreditamos que o texto traz contribuições significativas. Pudemos lançar luz a documentos significativos, redigidos pelo primeiro diretor da Escola Nacional de Belas Artes, Rodolpho Bernardelli; sobretudo o Relatório de 1891. A sua análise foi fundamental para elucidarmos a importância atribuída ao ensino desenvolvido de modo intuitivo, assim como a desordem que imperava na Academia antes da sua renovação e a sistematização e seriação do ensino consecutivas que foram impostas após a Reforma. Mostramos ainda como a Reforma da Academia fazia parte da Reforma Benjamin Constant, que ocorreu entre 1890 e 1891 - a primeira reforma educacional do período republicano. Acreditamos, destarte, ter conferido ao processo de transformação da Academia em Escola Nacional de Belas Artes a importância que lhe é devida, resgatando a sua relevância histórica como uma das principais medidas de transformação artístico-culturais no 


\section{RE ARTE \\ MODA \\ DESIGN}

| http://www.revistas.udesc.br/index.php/Ensinarmode

advento da República e reafirmando a esquecida autoridade que a Escola, como principal instituição de ensino artístico do país, representou para o recém-inaugurado governo republicano.

\section{REFERÊNCIAS}

BERNARDELLI, Rodolpho. Anexo H. Relatório Apresentado ao Presidente da República dos Estados Unidos do Brasil pelo Dr. João Barbalho Uchôa Cavalcanti, Ministro da Instrução Pública, Correios e Telégrafos, em maio de 1891.

BONNET, Alain. L'enseignement des arts au XIXe siècle. La réforme de l'École des beaux-arts de 1863 et la fin du modèle académique. Rennes: Presses universitaires de Rennes, 2006.

BOUILLON, Jean-Paul [et al]. La Promenade du Critique influent: Anthologie de la Critique d'Art en France 1850-1900. Paris : Hazan, 1990.

BROCOS, Modesto. A questão do ensino de Bellas Artes seguido da crítica sobre a direção Bernardelli e justificação do autor. Rio de Janeiro: s/e, 1915.

CAVALCANTI, Ana Maria Tavares. Anexo I do Relatório Final ao CNPq. O Conceito de Modernidade e a Academia Imperial de Belas Artes do Rio de Janeiro. Rio de Janeiro, 2004.

DAZZI, Camila. Por em prática e Reforma da antiga Academia: a concepção e a implementação da reforma que instituiu a Escola Nacional de Belas Artes em 1890. Rio de Janeiro, 2011. Tese (Doutorado em História da Arte) - PPGAV/UFRJ.

Decreto n. 1630, de 14 de maio de 1855. Estatutos da Academia de Belas Artes.

Decreto n.938 de 8 de novembro de 1890. Estatutos referentes a Instituição da Escola Nacional de Belas Artes e do Conselho Superior de Belas Artes.

Decreto No. 2424 de 25 de maio de 1859 que altera várias disposições dos Estatutos vigentes da Academia das Bellas Artes.

DUQUE ESTRADA, Luiz Gonzaga. Contemporâneos. Rio de Janeiro: s/e, 1929.

GALVÃO, Alfredo. Subsídios para a história da Academia Imperial e da Escola Nacional de Belas Artes. Rio de Janeiro, 1954.

LARROUMET, Gustav. L' Art et L'Etat en France. Paris : Librairie Hachette, 1895. p. 193, nota 2.

MARQUES, Luiz (org.). 30 mestres da pintura no Brasil. São Paulo: MASP/Rio de Janeiro: MNBA, 2001 (Catálogo de exposição).

MOREIRA MAIA, Ernesto Gomes. Relatório da Diretoria da Academia Imperial de Belas Artes ao Ministro Antônio Ferreira Vianna, em 26 de março de 1889, referente ao ano de 1888. 


\section{RE ARTE MODA DESIGN \\ | http://www.revistas.udesc.br/index.php/Ensinarmode}

NAGLE, Jorge. Educação e sociedade na Primeira República. Rio de Janeiro: E.P.U., 1974.

OLIVEIRA, Dilma Maria Andrade de. Reformas de ensino e a construção da escola pública republicana - 1889/1930: o caso de Sergipe. LOMBARDI, J. (org.). Navegando pela História da Educação Brasileira. Campinas: FE/HISTEDBR, 2006.

SEGRÉ, Monique. L'Art comme institution : l'École des Beaux-Arts, 19ème-20ème siècle. Paris : École Normal Sup. de Cachan, 1993

VITET, M. De l'enseigenment des arts du dessin. Revue des deux mundes, novembro de 1864 , p. $74-108$

Recebido em: 04/09/2017

Aceito em: 09/10/2017 